（2）大部分路段弯沉的公里代表值介于 15-25（0.01mm）之间, 只有个别路段公里代表值高于 $30(0.01 \mathrm{~mm})$ 。

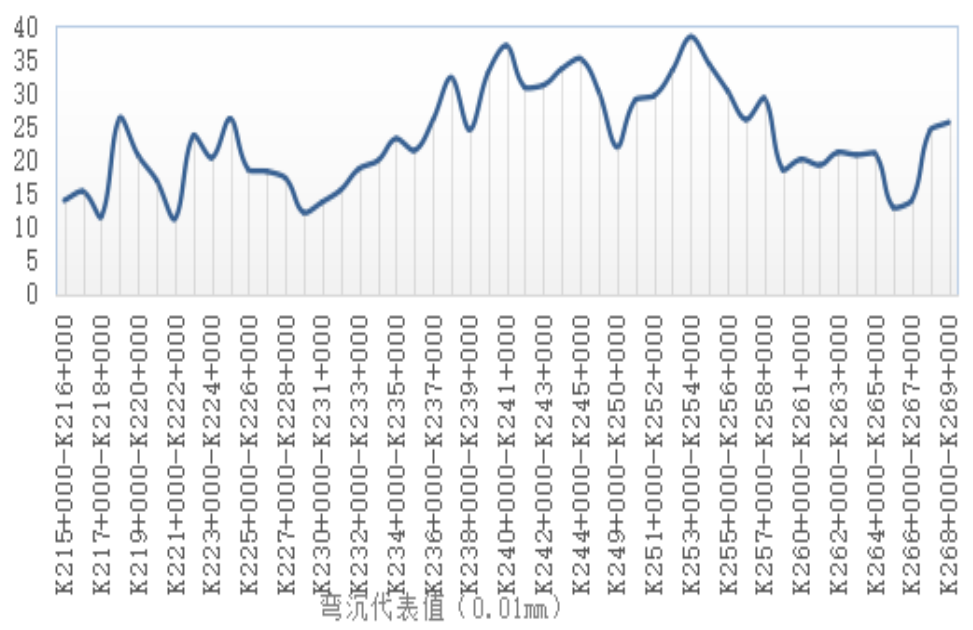

图 2 结构强度指数 PSSI 值随里程的变化曲线图

（3）弯沉盆模量, 面层模量主要集中在 10000-30000MPa 之间, 基层模量主要集中在 1000-4000MPa 之间, 路基模 量主要集中在 200-500MPa 之间。总体来说, 上行方向硬路肩路面、基层、路基的强度较好, 路面整体结构强度很好。

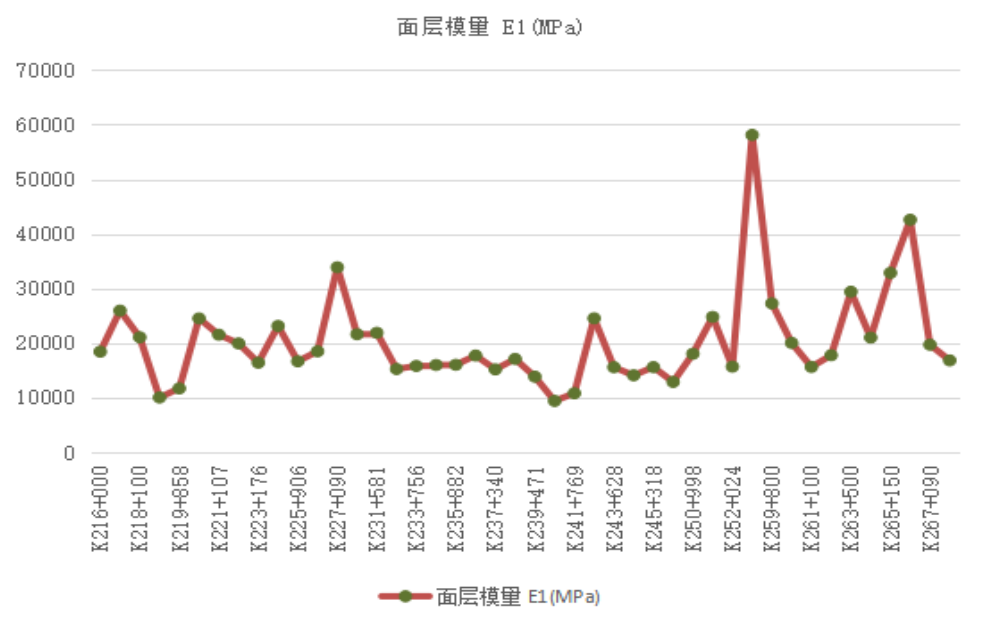

图 3 面层模量随里程的变化曲线图

基层模里 $\mathrm{E} 2(\mathrm{MP} \mathrm{P})$

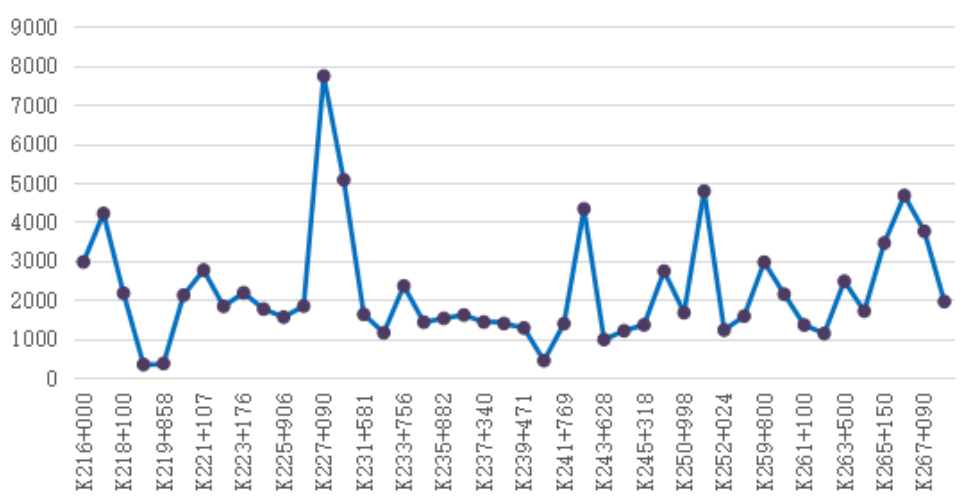

$\rightarrow$ 基层模里 E2(MPa)

图 4 基层模量随里程的变化曲线图 


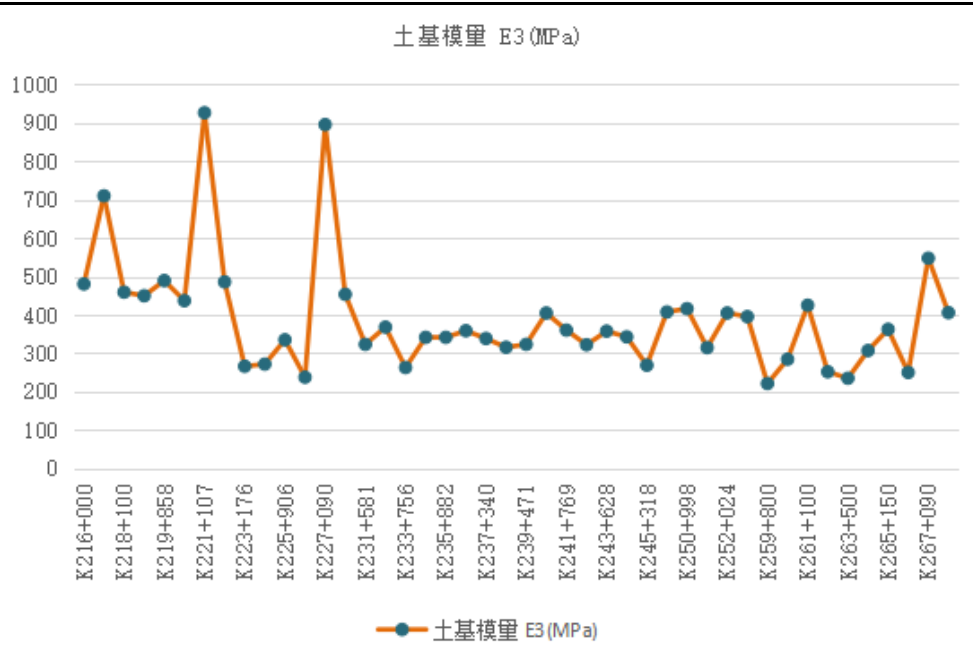

图 5 土基模量随里程的变化曲线图

(4) 取芯检测

通过取芯情况分析, 硬路肩病害较少, 可见病害均为横向或纵向裂缝, 沥青层全部芯样 (除个别裂缝处外) 总体 较完整。

(5) 探坑

本次路面结构层模量检测选择典型路段, 采取人工挖孔的方式, 对挖孔处路面结构层分层进行调查和描述, 并测 定路面各个结构层的模量, 评价各结构层的稳定性。

表 1 硬路肩结构层模量检测结果汇总表

\begin{tabular}{|c|c|c|c|c|c|c|c|c|}
\hline 桩号 & $\begin{array}{l}\text { 上面层顶 } \\
\text { 面回弹模 } \\
\text { 量 }(\mathrm{MPa})\end{array}$ & $\begin{array}{l}\text { 中面层顶 } \\
\text { 面回弹模 } \\
\text { 量 }(\mathrm{MPa})\end{array}$ & $\begin{array}{l}\text { 上基层顶 } \\
\text { 面回弹模 } \\
\text { 量 }(\mathrm{MPa})\end{array}$ & $\begin{array}{l}\text { 中基层顶 } \\
\text { 面回弹模 } \\
\text { 量 }(\mathrm{MPa})\end{array}$ & $\begin{array}{l}\text { 下基层层 } \\
\text { 顶回弹模 } \\
\text { 量 }(\mathrm{MPa})\end{array}$ & $\begin{array}{l}\text { 底基层层 } \\
\text { 顶回弹模 } \\
\text { 量 }(\mathrm{MPa})\end{array}$ & $\begin{array}{c}\text { 路床顶面 } \\
\text { 回弹模量 } \\
(\mathrm{MPa})\end{array}$ & $\begin{array}{c}\text { 距路床 } \\
30 \mathrm{~cm} \text { 回弹 } \\
\text { 模量 }(\mathrm{MPa})\end{array}$ \\
\hline $\mathrm{K} 217+400$ & \multicolumn{3}{|c|}{ 已铣刨 } & 4159. 09 & 614.09 & 225.37 & 86.11 & 52.46 \\
\hline $\mathrm{K} 217+900$ & \multicolumn{4}{|c|}{ 已铣刨 } & 1307.14 & 128.69 & 91.28 & 126.78 \\
\hline $\mathrm{K} 253+600$ & 1759.62 & 1188.31 & 1326. 09 & 1345.59 & 1830 & 281.54 & 34.32 & 57.29 \\
\hline $\mathrm{K} 220+870$ & 1562.5 & 729.17 & 1048.8 & 2734.38 & 870.03 & 344.88 & 207.8 & 173.74 \\
\hline $\mathrm{K} 225+100$ & 933.69 & 550.81 & 632.75 & 622.46 & 321.69 & 134.56 & 30.78 & 38.34 \\
\hline $\mathrm{K} 229+010$ & 1780.52 & 2069.26 & 1392.05 & 1906.25 & 1115.85 & 243.35 & 49.87 & 32.07 \\
\hline $\mathrm{K} 255+600$ & 1158.23 & 1051.72 & 2178.57 & 1005.49 & 2127.91 & 462.12 & 59.12 & 50.17 \\
\hline $\mathrm{K} 260+350$ & 933.69 & 430.13 & 575.66 & 983.87 & 905.94 & 341.42 & 61.44 & 77.36 \\
\hline $\mathrm{K} 264+300$ & 1472.36 & 384.74 & 362.86 & 870.03 & 922.44 & 546.88 & 42.91 & 201.87 \\
\hline
\end{tabular}

通过以上检测数据可以看出：上面层顶面回弹模量在 900-1800MPa 之间，中面层顶面回弹模量在 350-120MPa 之间, 上基层顶面回弹模量离散性较大，中基层顶面回弹模量大部分数据在 900-2000MPa 之间，下基层顶面回弹模量离散性较 大, 底基层顶面回弹模量大部分数据在 200-500MPa 之间, 路床顶及距路床 30cm 回弹模量大部分数据在 30-70MPa 之间。

根据检测结果, 硬路肩铣刨至新拼宽路床顶面, 剩余路床（宽度范围含老路硬路肩、拼缝、新拼宽部分）完整、 无病害, 且满足验收条件时（最不利季节路床顶面的回弹模量值要求大于 $40 \mathrm{Mp}$, 弯沉值小于 $232.9(0.01 \mathrm{~mm}$ ), 然后再 进行水稳底基层施工。因此旧路路肩需要按要求进行反开挖铣刨处理, 并需要对反开挖部位路床回弹模量值以及弯沉 值不符合要求的段落进行处理。

\section{2 反开挖处理方案}

根据旧路沥青路面高程复测结果, 计算拟合设计高与旧路标高拟合高差 $\mathrm{h}$, 根据设计图纸纵断面找平结构图逐段落 确定不同拟合高差情况下的旧路找平结构形式及旧路各结构层铣刨方案。本项目经测量复测后反开挖处理方案为:

铣刨台阶形式同路面结构层厚度, 分别为 $8 \mathrm{~cm} 、 10 \mathrm{~cm} 、 20 \mathrm{~cm} 、 20 \mathrm{~cm} 、 20 \mathrm{~cm}$, 台阶宽度为 $15 \mathrm{~cm} 、 20 \mathrm{~cm} 、 20 \mathrm{~cm} 、 20 \mathrm{~cm}$, 铣刨后最底层宽度为 $3.15 \mathrm{~m}$ 。铣刨完成后, 对路槽底部路床进行换填 $6 \%$ 灰土处理, 换填厚度 $40 \mathrm{~cm}$, 增强路床承载能力, 
减小拼宽路面的沉降。新建路面的结构层为水泥稳定碎石底基层 $20 \mathrm{~cm}$ 厚、水泥稳定碎石基层 $40 \mathrm{~cm}$ 厚、 $10 \mathrm{~cm}$ 厚 ATB- 25 、 $8 \mathrm{~cm}$ 厚 $\mathrm{AC}-25 、 6 \mathrm{~cm}$ 厚 $\mathrm{AC}-20 、 4 \mathrm{~cm}$ 厚 SMA-13。如图 6 所示。

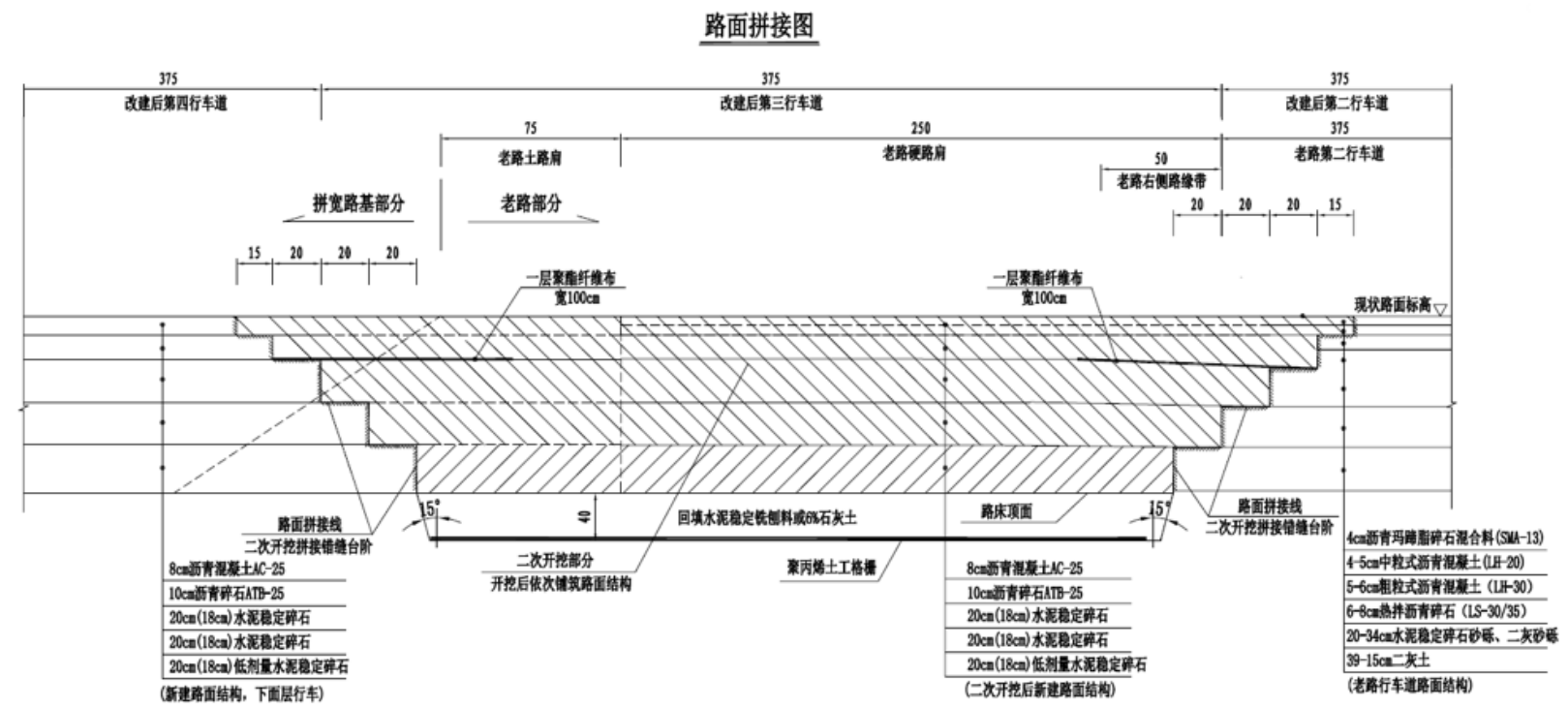

图 6 反开挖路面拼接断面图

现场铣刨后的台阶宽度、高度必须符合要求，纵向线形顺适，铣刨彻底无病害，无夹层。

\section{3 路面拼接施工关键技术}

\section{1 路基处理}

（1）路面结构层分层铣刨完成后, 对老路路床进行换填处理, 处理厚度共 $40 \mathrm{~cm}$ 厚 $6 \%$ 灰土。灰土处理分两层进行, 每层处理厚度为 $20 \mathrm{~cm}$, 施工时首先将路床顶层 $20 \mathrm{~cm}$ 填土挖除至老路路面, 老路路面应做好防污染措施, 过程中设置专 人指挥，检查处理深度，防止超挖或欠挖。

（2）灰土施工时，石灰撒布采用装载机配合人工进行撒布，确保撒布均匀，石灰撒布后，采用专用路拌机进行拌 合, 拌合处理深度要求不少于 $20 \mathrm{~cm}$ 。拌合的同时随机进行石灰剂量检测取样, 进行石灰灰剂量检测, 现场严格控制灰 剂量, 同时还应加强对石灰原材检测, 确保原材质量合格。

(3) 灰土拌和完成后, 采用平地机对路床进行精平处理, 保证路床平整度, 再采用 $22 \mathrm{t}$ 单钢轮压路机进行碾压, 碾压完成后采用三钢轮压路机对台阶根部进行碾压处理，确保接缝处碾压密实。

（4）灰土处理完成后, 应加强对路床结构层养生处理, 采用酒水以及塑料薄膜覆盖养或土工布覆盖养生, 养生时 间不低于 $7 \mathrm{~d}$ 。

（5）待养生时间结束后，按段落采用贝克曼梁进行路床顶面弯沉值检测，验收弯沉值按不大于 $155.3 \mathrm{~mm}$ 控制（因反 开挖车道属于第三车道, 为重车行车道, 路床弯沉验收以拼宽路床验收标准执行), 经现场检测, 弯沉值代表值如下表:

表 2 硬路肩弯沉检测汇总表

\begin{tabular}{c|c|c}
\hline 序号 & 桩号 & 弯沉代表值 $(0.01 \mathrm{~mm})$ \\
\hline 1 & $\mathrm{~K} 215+000-\mathrm{k} 216+000$ & 111.7 \\
\hline 2 & $\mathrm{~K} 216+000-\mathrm{k} 217+000$ & 114.3 \\
\hline 3 & $\mathrm{~K} 217+000-\mathrm{k} 218+000$ & 124.6 \\
\hline 4 & $\mathrm{~K} 219+000-\mathrm{k} 220+000$ & 120.4 \\
\hline 5 & $\mathrm{~K} 221+000-\mathrm{k} 222+000$ & 122.9 \\
\hline 6 & $\mathrm{~K} 222+000-\mathrm{k} 223+000$ & 115.1 \\
\hline 7 & $\mathrm{~K} 223+000-\mathrm{k} 224+000$ & 122.9 \\
\hline 8 & $\mathrm{~K} 224+000-\mathrm{k} 225+000$ & 137.6 \\
\hline
\end{tabular}

（6）老路路面铣刨后，由于路面铣刨较快，后期灰土路床施工进度较慢，路床长时间暴露在空气中，且铣刨后路 